\title{
Aches and Pains in a Patient With History of Prostatectomy: Extensive Skeletal Metastases Picked up by Diffusion- Weighted Magnetic Resonance Imaging
}

\author{
Abraham M. Ittyachen ${ }^{\mathrm{a}, \mathrm{c}}$, Meera Radhakrishnan ${ }^{\mathrm{a}}$, Thomas Kuncheria ${ }^{\mathrm{a}}$, Rajeev Anand ${ }^{\mathrm{b}}$
}

\begin{abstract}
A 64-year-old gentleman presented to the out-patient with complaints of generalized body ache. He had a history of prostate cancer for which robotic radical prostatectomy (RP) was done earlier. The levels of prostate specific antigen (PSA) and alkaline phosphatase (ALP) were significantly elevated. Skeletal radiograph showed only few sclerotic foci. Magnetic resonance imaging whole-body diffusionweighted image (MRI-WB-DWI) however revealed the presence of diffuse skeletal metastases. In any elderly male who presents with generalized body pain, eliciting a good history should not be overlooked. With a history of prostate cancer, diffuse metastases should be high in the list of differential diagnosis. Though there are several imaging methods to detect metastases, MRI-WB-DWI is a welcome alternative to the established methods. Patients who undergo RP for prostate cancer should be counselled regarding the importance of follow-up of their PSA levels.
\end{abstract}

Keywords: Generalized body ache; Prostate cancer; Radical prostatectomy; Diffuse skeletal metastases; Prostate specific antigen

\section{Introduction}

Prostate cancer is one of the leading causes of cancer death in males around the world [1]. In India there is substantial heterogeneity among the provinces in the incidence rate of different types of cancer [2]. The province of Kerala leads the country in

Manuscript submitted July 8, 2020, accepted July 15, 2020

Published online August 6, 2020

aDepartment of Medicine, Malankara Orthodox Syrian Church Medical College and Hospital, Kolenchery, Ernakulam District, Kerala State 682311, India bepartment of Radiodiagnosis, Malankara Orthodox Syrian Church Medical College and Hospital, Kolenchery, Ernakulam District, Kerala State 682311, India

${ }^{\mathrm{c} C}$ Corresponding Author: Abraham M. Ittyachen, Department of Medicine, Malankara Orthodox Syrian Church Medical College and Hospital, Kolenchery, Ernakulam District, Kerala State 682311, India.

Email: abyliz@rediffmail.com

doi: https://doi.org/10.14740/jmc3545 the crude cancer incidence rate [2]. While prostate cancer had the fifth highest cancer incidence rate among males in India in 2016 [2], the crude incidence rate for prostate cancer was highest in Kerala [2].

Osseous metastases is the most common metastatic site in prostate cancer and is well described [3]. Other sites described are less frequent and include distant lymph nodes, liver, lungs, pleura, brain, digestive system, retroperitoneum, kidney and adrenal gland [3]. For localized prostate cancer radical prostatectomy (RP) has remained the primary mode of treatment with good outcome. The introduction of minimally-invasive (robotic-assisted) surgical techniques is considered an important milestone in RP [4]. However, $20-40 \%$ of patients with clinically localized prostate cancer will have a biochemical recurrence (BCR) after RP [5], which is a state of an increasing level of prostate specific antigen (PSA) after treatment of prostate cancer by prostatectomy or radiation therapy. BCR can be predictive of the development of subsequent distant metastases and mortality, and often predates other signs of clinical progression by several years [6]. Most cases of BCR usually occur in the early period (within 5 years after RP) while some cases occur in the late period ( $>5$ years after RP) [7], and follow-up of PSA level is the most important tool in the surveillance of prostate cancer recurrence.

\section{Case Report}

A 64-year-old gentleman presented to the out-patient (OP) with complaints of generalized body ache, tiredness, anorexia and loss of weight. He was suffering from these symptoms since the previous 3 weeks. He had a past history of diabetes mellitus and hypertension, both of which were under fairly good control. He also had a history of prostate cancer for which robotic RP was done 3 years ago from another center, the details of which were not available. Though he was advised regular follow-up from that center, he was highly irregular. He occasionally had a binge of alcohol but denied use of any narcotic substances. On examination vitals were within normal limits. Systemic examination was unremarkable except for a mild, soft hepatomegaly.

Hemogram was within normal limits. But the erythrocyte sedimentation rate (ESR) was elevated $(83 \mathrm{~mm} / \mathrm{h})$. Serum protein electrophoresis did not show any features of multiple myeloma. The level of PSA was significantly elevated (> $100 \mathrm{ng} /$ 


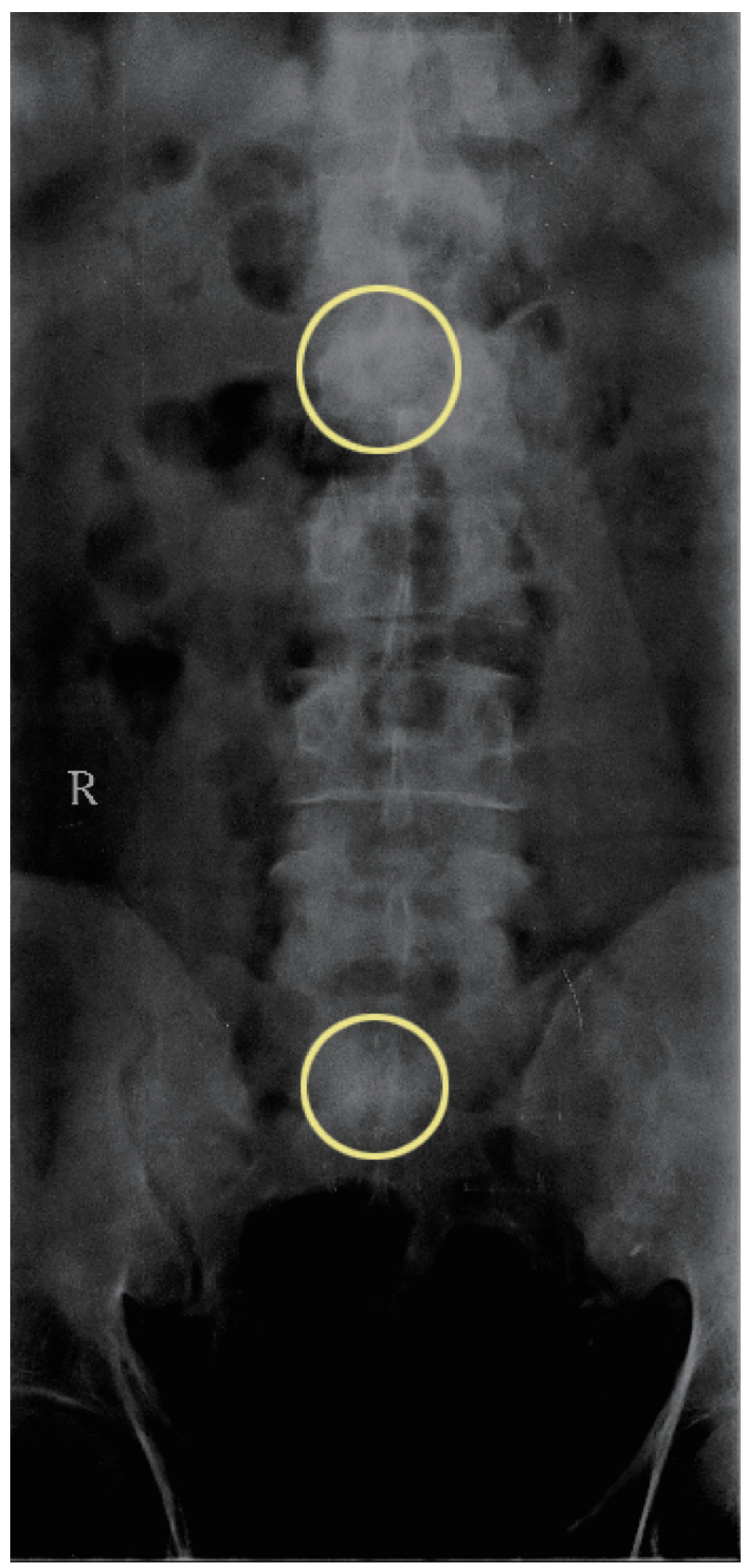

Figure 1. Sclerotic foci in lumbar vertebra and sacrum (circles).

$\mathrm{mL}$; normal: up to $4 \mathrm{ng} / \mathrm{mL}$ ). Alkaline phosphatase (ALP) was also considerably raised (769 U/L; normal: 38 - $126 \mathrm{U} / \mathrm{L})$.

Imaging studies including ultrasound abdomen, radiograph of the skull and lumbosacral spine; and magnetic resonance imaging whole-body diffusion-weighted image (MRI-WBDWI) was done. Ultrasound abdomen showed the presence of mild fatty liver. Radiograph of the skull was essentially normal. Radiograph of the vertebrae and hip showed few sclerotic foci in the lumbar vertebrae and sacrum (Fig. 1). MRI-WBDWI however revealed the presence of diffuse skeletal metastases (Fig. 2a, b). Areas of restricted diffusion involving the pelvic bones, multiple vertebral bodies, bilateral scapula, bi-

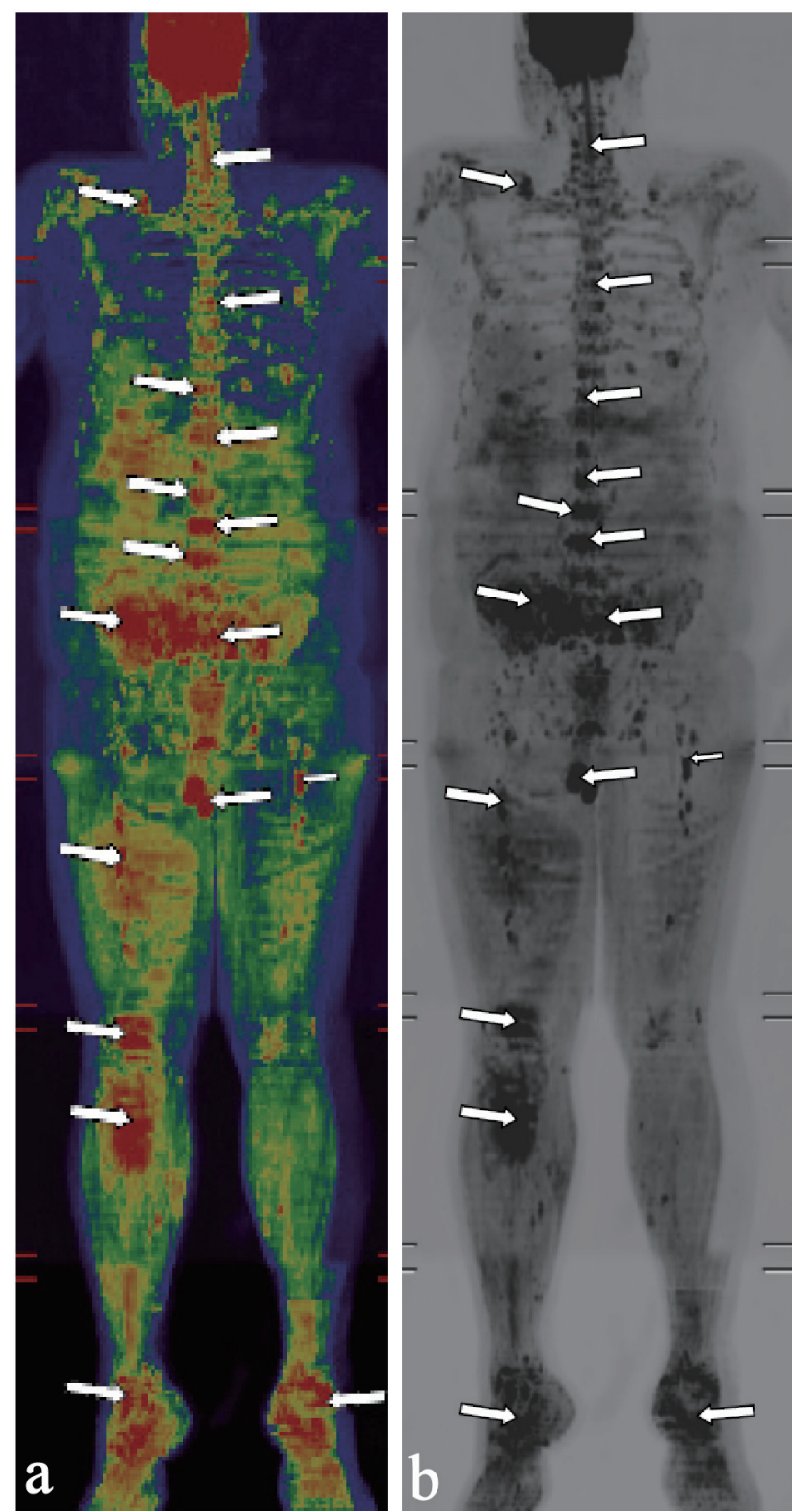

Figure 2. (a) Magnetic resonance imaging whole-body diffusionweighted image (MRI-WB-DWI) showing presence of diffuse metastases in color (arrows). (b) MRI-WB-DWI showing presence of diffuse metastases in black and white (arrows).

lateral upper humeri and sternum were noted. Patchy areas of restricted diffusion was noted in the ribs bilaterally and upper metaphysis of the left tibia. Restricted diffusion was also noted in the paravertebral soft tissues at the level of lumbar vertebrae and iliopsoas bilaterally. Restricted diffusion of bilateral inguinal lymph nodes was also appreciated.

Patient was referred to a center with oncology facilities and since then was lost to follow-up.

\section{Discussion}

Here we have an elderly gentleman presenting with diffuse 
body pain, anorexia and loss of weight. Differential diagnosis would include multiple myeloma, systemic lupus erythematosus (SLE), polymyalgia rheumatica and giant cell arteritis [8]. Other differential diagnosis that should be considered includes solid organ malignancies, hematological malignancies and seronegative symmetric polyarthritis [9]. The clue in our patient lay in the history; he had a history of prostate cancer. And with elevated levels of PSA and ALP the diagnosis was none too obvious.

PSA is produced almost exclusively by prostatic epithelial cells and usually reaches undetectable levels within 21 - 30 days after RP [10]. Hence persistent serum PSA levels or rising PSA levels after RP indicates residual prostate cancer or recurrence. The usual practice is to check the first PSA level sometime between 1 and 3 months after surgery, and every 3 months thereafter, at least for the first year or two and thereafter annually [11]. Most cases of BCR usually occur in the early period (within 5 years after RP) while some cases occur in the late period ( $>5$ years after RP) [7]. Our patient did not have any regular follow-up after his surgery. It was the generalized myalgia that had forced him to seek medical attention.

BCR after RP is always followed up with imaging. Medical imaging has an important role in the follow-up of BCR not to mention its role in the staging, restaging and therapy of prostate cancer. Radionuclide bone scanning and computed tomography (CT) have traditionally been used to image disease spread [12]. Now more sensitive imaging methods are available for detecting evidence of metastases, even when conventional imaging shows no signs of metastases. Positron emission tomography (PET) with prostate-specific membrane antigen (PSMA) or with choline or fluciclovine; and whole-body MRI, are making it possible for earlier and improved identification of metastases [12, 13]. MRI-WB-DWI is comparable to PET in the detection of metastases [14]. It also offers an advantage in that its use does not lead to ionization radiation exposure [15].

The role of radiography in the detection of metastases in prostatic malignancy has largely become historical. As was shown in this case, radiograph of the vertebrae and hip showed only few sclerotic foci but MRI-WB-DWI revealed the presence of extensive metastases.

\section{Conclusions}

In conclusion any elderly male who presents with generalized body pain, eliciting a good history should not be overlooked. With a history of prostate cancer, diffuse metastases should be high in the list of differential diagnosis. Though there are several imaging methods to detect metastases, MRI-WB-DWI is a welcome alternative to the established methods. It cannot be better emphasized that patients who undergo RP for prostate cancer should be counselled regarding the importance of follow-up of their PSA levels as protocol dictates in any case of prostate cancer.

\section{Acknowledgments}

None to declare.

\section{Financial Disclosure}

None to declare.

\section{Conflict of Interest}

None to declare.

\section{Informed Consent}

The patient described in the case report had given informed consent for the case report to be published.

\section{Author Contributions}

AMI was involved in the case selection and drafting of the manuscript. MR and TK were also involved in the case selection. RA was involved in the interpretation of the images.

\section{Data Availability}

All data and information regarding this manuscript are present within the text.

\section{References}

1. Bray F, Ferlay J, Soerjomataram I, Siegel RL, Torre LA, Jemal A. Global cancer statistics 2018: GLOBOCAN estimates of incidence and mortality worldwide for 36 cancers in 185 countries. CA Cancer J Clin. 2018;68(6):394424.

2. India State-Level Disease Burden Initiative Cancer C. The burden of cancers and their variations across the states of India: the Global Burden of Disease Study 19902016. Lancet Oncol. 2018;19(10):1289-1306.

3. Vinjamoori AH, Jagannathan JP, Shinagare AB, Taplin ME, Oh WK, Van den Abbeele AD, Ramaiya NH. Atypical metastases from prostate cancer: 10-year experience at a single institution. AJR Am J Roentgenol. 2012;199(2):367372.

4. Schrader AJ, Muller J, Janssen M, Krabbe LM. [Radical prostatectomy through the years]. Aktuelle Urol. 2019;50(5):486-490.

5. Tourinho-Barbosa R, Srougi V, Nunes-Silva I, Baghdadi M, Rembeyo G, Eiffel SS, Barret E, et al. Biochemical recurrence after radical prostatectomy: what does it mean? Int Braz J Urol. 2018;44(1):14-21.

6. Paller CJ, Antonarakis ES. Management of biochemically recurrent prostate cancer after local therapy: evolving standards of care and new directions. Clin Adv Hematol Oncol. 2013;11(1):14-23.

7. Loeb S, Feng Z, Ross A, Trock BJ, Humphreys EB, Walsh PC. Can we stop prostate specific antigen testing 10 years 
after radical prostatectomy? J Urol. 2011;186(2):500-505.

8. Gonzalez-Gay MA, Garcia-Porrua C, Salvarani C, Olivieri I, Hunder GG. Polymyalgia manifestations in different conditions mimicking polymyalgia rheumatica. Clin Exp Rheumatol. 2000;18(6):755-759.

9. Gonzalez-Gay MA, Garcia-Porrua C, Salvarani C, Olivieri I, Hunder GG. The spectrum of conditions mimicking polymyalgia rheumatica in Northwestern Spain. J Rheumatol. 2000;27(9):2179-2184.

10. Stamey TA, Kabalin JN, McNeal JE, Johnstone IM, Freiha F, Redwine EA, Yang N. Prostate specific antigen in the diagnosis and treatment of adenocarcinoma of the prostate. II. Radical prostatectomy treated patients. J Urol. 1989;141(5):1076-1083.

11. Aus G, Abbou CC, Pacik D, Schmid HP, van Poppel H, Wolff JM, Zattoni F, et al. EAU guidelines on prostate cancer. Eur Urol. 2001;40(2):97-101.
12. Sartor O, de Bono JS. Metastatic prostate cancer. N Engl J Med. 2018;378(7):645-657.

13. Lecouvet FE, El Mouedden J, Collette L, Coche E, Danse E, Jamar F, Machiels JP, et al. Can whole-body magnetic resonance imaging with diffusion-weighted imaging replace Tc $99 \mathrm{~m}$ bone scanning and computed tomography for single-step detection of metastases in patients with high-risk prostate cancer? Eur Urol. 2012;62(1):68-75.

14. Eschmann SM, Pfannenberg AC, Rieger A, Aschoff P, Muller M, Paulsen F, Anastasiadis A, et al. Comparison of $11 \mathrm{C}$-choline-PET/CT and whole body-MRI for staging of prostate cancer. Nuklearmedizin. 2007;46(5):161-168; quiz N147-168.

15. Stecco A, Trisoglio A, Soligo E, Berardo S, Sukhovei L, Carriero A. Whole-body MRI with diffusion-weighted imaging in bone metastases: a narrative review. Diagnostics (Basel). 2018;8(3). 